\title{
THÉÂTRE ET MÉTATHÉÂTRE DANS L'OEUVRE DE LUIS RIAZA
}

\section{Carole EGGER}

(Strasbourg: Presses Universitaires de Strasbourg, 2014, 282 págs.)

La profesora Carole Egger, catedrática de Literatura española en la Universidad de Estrasburgo, presenta en esta monografía un estudio de gran profundidad y erudición sobre la dramaturgia de Luis Riaza, otorgando especial atención a la obra Retrato de dama con perrito, así como al resto de piezas de este autor que también componen el "ciclo sobre el poder": El desván de los machos y el sótano de las hembras, Los perros y El palacio de los monos. Acompaña el estudio una cuidada traducción de Retrato de dama, realizada por la propia autora, y seis anexos en los que se incluyen materiales de gran interés para investigadores y estudiosos del teatro contemporáneo español: un texto inédito firmado por Luis Riaza, una bibliografía completa y actualizada de este autor y recopilaciones tanto de las traducciones existentes como de las puestas en escena de los textos de Riaza que se han realizado en España y en el extranjero. Aporta, además, un índice onomástico y terminológico. Cierra el volumen una reproducción del método de estudio del texto teatral de Michel Vinaver, originalmente incluido en Écritures dramatiques, publicado en la editorial Actes Sud en 1993, que la profesora Egger emplea para su análisis de Retrato de dama.

El estudio realizado por la profesora Egger supone la culminación de sus investigaciones sobre los autores del "Nuevo Teatro", como Romero Esteo o el propio Luis Riaza, de los que es una especialista reconocida internacionalmente, y a los que ha consagrado numerosos artículos, capítulos de libro, traducciones y presentaciones en congresos. En este sentido, cabe destacar la valiosa labor de difusión del Nuevo Teatro que la profesora Egger ha desarrollado desde el equipo de investigación CHER de la Universidad de Estrasburgo a través de proyectos de investigación -como el que dirige en el marco del proyecto de excelencia más amplio PLaTeaU (Plateforme pour les Langues et le Théâtre à I'Université de Strasbourg, Orient-Occident, XXle siècle)-, dirección de tesis doctorales, organización de congresos, publicaciones y jornadas de estudio, lo que sin duda ha favorecido el conocimiento de dichos dramaturgos en Francia. En este contexto, sobresale la organización que llevó a cabo del congreso “Nuevo Teatro y Transición (19751985)", celebrado en la Universidad de Estrasburgo en octubre de 2012, momento en el que se reunieron por primera vez en Francia especialistas, dramaturgos, directores y actores vinculados al Nuevo Teatro. 
La profesora Carole Egger se dirige en este estudio a un lector especializado, pero esto no significa que su monografía sólo tenga interés para los ya conocedores del teatro de Luis Riaza. Por el contrario, se trata de un trabajo que introduce grandes aportaciones para el estudio del teatro español contemporáneo y, más generalmente, para la comprensión de las distintas formas de "anti-teatro" que, inscribiéndolas en la tradición de Shakespeare, Calderón, Pirandello o Beckett, Egger reinterpreta en el contexto de creación español de los años sesenta y setenta del siglo pasado. Además, dada la profundidad teórica de la monografía, que reproduce y pone en práctica el método de análisis de Michel Vinaver, esta obra también despertará un gran interés entre los teóricos del teatro así como entre todos aquellos investigadores que dediquen sus trabajos a pensar la teatralidad del texto dramático contemporáneo.

Nacido en 1925, Luis Riaza escribe sus primeros textos teatrales durante los años sesenta del siglo pasado. Como apunta Egger en la introducción, su obra da cuenta de una generación de autores -a la que también pertenecen Francisco Nieva o Romero Esteo- que estuvieron marcados por un doble condicionamiento socio-histórico: el que procede de la propia historia del teatro occidental contemporáneo y el que le impone la sociedad española del momento, que continuará bajo el peso de la dictadura franquista hasta bien entrados los años setenta. De este modo, el teatro de Luis Riaza es heredero del "anti-teatro" occidental (Artaud, Kantor, Brecht, Grotowski) que había hecho saltar en mil pedazos las convenciones de la mimesis, pero también supone una reacción ante la generación realista española"qui avait cru pouvoir faire des planches un espace privilégié de contestation politique" (p. 6). La profesora Egger se acercará a la dramaturgia de Riaza desde este doble prisma: por un lado, tratará de inscribirla en la historia del teatro occidental pero, por otro, también mostrará que su obra es sintomática de la época de transición política española.

Retrato de dama con perrito, la obra a la que se dedica la mayor atención crítica en la monografía, constituye un texto de referencia dentro de la producción dramática de Luis Riaza. Publicada originalmente en la editorial Fundamentos en 1976 (con prólogo de Francisco Nieva), fue puesta en escena por distintos grupos de teatro independiente como"La Picota" o"Teatro Cero"y, ya en 1979, se estrenó en el Centro Dramático Nacional bajo la dirección de Miguel Narros. Benito, Francisca, Gran Dama y Artista Adolescente son los cuatro personajes que en dicho montaje representaron Paco Guijar, Socorro Anadón, Berta Riaza e Imanol Arias respectivamente. Se trata de una pieza de fuerte contenido alegórico y poético que, multiplicando ceremonias y rituales, rompe con la estética realista a través de un lenguaje barroco, plagado de referencias eruditas, en el que se abordan, en un juego infinito de cajas chinas, temáticas relacionadas con el poder, los juegos con las identidades imaginadas, la perversión o la muerte. 
El propósito de la profesora Egger en su estudio está dirigido, fundamentalmente, a catalogar las distintas formas meta-teatrales que emergen de los textos de Riaza y que invitan a inscribir su obra "dans la tradition d'une forme d'anti-théâtre qui depuis Calderón et Shakespeare, en passant par Pirandello, Beckett et Genet, s'est ingénié à confondre, mélanger et estomper les contours des frontières entre vie et théâtre" ( $p$. 193). La utilización casi obsesiva del dispositivo del teatro dentro del teatro, las puestas en abismo y las estructuras en cajas chinas evidencian -según el análisis de Egger- una voluntad por parte de Riaza -diríase que incluso premeditada y metódica- de poner en evidencia todos los elementos que constituyen el teatro para proceder, inmediatamente, a su demolición. En este sentido, apunta Egger, la obra de Luis Riaza es fiel hija de su tiempo: "Témoin fidèle de la création artistique de son temps, l'œuvre montre à la fois la capacité centrifuge du théâtre occidental contemporain à intégrer toutes les autres formes d'expression -plastique, chorégraphique, musicale, picturale- mais illustre également l'instabilité et l'indétermination qui caractérisent tout drame moderne" (p. 194).

El resultado de estos juegos ceremoniales infinitos es la creación de un universo dramático que pretende dar testimonio del nacimiento de un mundo y una palabra "nuevos". Para ello, Riaza realiza una reinterpretación de todas las dramaturgias del pasado, del misterio medieval al teatro del absurdo, pasando por el drama romántico o el esperpento. El resultado, en palabras de Egger, es una obra original e innovadora que, junto a otras joyas notables del Nuevo Teatro, representa un momento cumbre del repertorio español contemporáneo posterior a Valle-Inclán.

El método de análisis del texto teatral concebido por Michel Vinaver -a quien la profesora Egger agradece no sólo haber autorizado su reproducción sino también haber leído y comentado personalmente el capítulo inspirado en él- resulta extremadamente útil y eficaz para los propósitos que se marca. Como ella misma subraya, un análisis detallado de la construcción progresiva del universo dramático a partir de distintos ejes dramatúrgicos como el que propone Vinaver permite poner en evidencia los principios fundamentales que rigen la escritura dramática de Luis Riaza. El método conjuga flexibilidad y rigor, y permite integrar todas las perspectivas críticas sin por ello perder el hilo conductor, siempre orientado hacia la dimensión dramática del texto. La inocencia teórica sin a priori estipulada por Vinaver desemboca en el descubrimiento en vivo del autor. Por otro lado, el método permite concebir la traducción -que la profesora Egger presenta al final de su estudio- como un texto teatral original, y de ahí que haya prestado especial atención a destacar en ella la teatralidad del propio texto. Cabe mencionar que la obra fue puesta en escena con esta versión en francés en 1985 en la ciudad de Lille por la compañía Martine Cendre. 
El estudio de la profesora Egger ofrece, en definitiva, claves de lectura fundamentales para abordar la dramaturgia de Luis Riaza. El lector encontrará pistas de reflexión y herramientas teóricas que le permitirán adentrarse en los mundos dramáticos de este autor, todavía poco conocido y estudiado, y descubrir así los principios que rigen su escritura. Se trata de un estudio de referencia obligada para los investigadores del Nuevo Teatro, pero también lo recibirán con gran interés todos aquellos interesados en comprender la evolución del dispositivo del teatro dentro del teatro y la miríada de formas meta-teatrales a las que ha dado lugar desde la época barroca. Por su erudición, peso teórico y conocimiento profundo del autor se trata de una aportación de gran valía tanto para el hispanismo como para los estudios dramatúrgicos, y la publicación en Francia de este volumen sin duda contribuirá a ampliar la difusión de este autor más allá de nuestras fronteras.

Cristina Oñoro Otero

Universidad de Estrasburgo 